\title{
The mineness of experience
}

\author{
Wolfgang Fasching
}

Published online: 26 May 2009

(C) The Author(s) 2009. This article is published with open access at Springerlink.com

\begin{abstract}
In this paper I discuss the nature of the "I" (or "self") and whether it is presupposed by the very existence of conscious experiences (as that which "has" them) or whether it is, instead, in some way constituted by them. I argue for the former view and try to show that the very nature of experience implies a nonconstituted synchronic and diachronic transcendence of the experiencing "I" with regard to its experiences, an "I" which defies any objective characterization. Finally I suggest that the self, though irreducible to inter-experiential relations, is not a "separately existing entity", but should be conceived of as a dimension, namely the dimension of first-personal manifestation of the experiences.
\end{abstract}

Keywords Self · Consciousness - Unity of consciousness · Personal identity

Remember, you are neither your body nor your mind. And you are not your mind added to your body. Then what are you?

$$
\text { Yasutani Roshi }{ }^{1}
$$

In the following I wish to discuss the nature of the "I" (the subject of experience, or self) and whether it is presupposed by the very existence of conscious experiences (as that which "has" them) or whether it is, instead, in some way constituted by them. I will argue for the former view and try to show that the very nature of experience implies a non-constituted synchronic and diachronic transcendence of the experiencing "I" with regard to its experiences, an "I" which has a purely subjective being and defies any objective characterization. Finally I will suggest that the self, though irreducible to inter-experiential relations, is not a

\footnotetext{
1 Kapleau (1980, p. 155).

W. Fasching $(\bowtie)$

Department of Philosophy, University of Vienna, Vienna, Austria

e-mail: w.fasching@univie.ac.at
} 
"separately existing entity", but should be conceived of as a dimension, namely the dimension of first-personal manifestation of the experiences.

\section{I and my experience}

Today, after decades of a purely physicalistic-reductionist opinio communis, it is not uncommon in philosophy of mind to grant that there is something irreducibly subjective about conscious experience, i.e. that a certain "first-personal mode of presentation" belongs to its very being. Experiences exist by being subjectively experienced, and this being-experienced implies a mode of givenness in which the experience is exclusively given to the respective experiencer herself. But who or what is this "experiencer" to whom the experience is exclusively given in this way? What is the "first person" of privileged "first-personal access" to "one's own" experiences? There is something puzzling about this.

I am having manifold conscious experiences right now. Yet what does it mean that $I$ have these experiences? Obviously they do not just exist; and it is also not enough to add that they exist by being subjectively experienced; they are experienced by me. What is this "me" that "has" these experiences?

The supposition of an "ego"-entity (the "self") that "has" the experiences has always encountered a great deal of scepticism as simply not being supported by any observable facts: When we sincerely introspect-as Hume famously noted-we do not find anything like a self: We only find our ever-changing experiences. Along a similar line, Lichtenberg wrote: "We know only the existence of our sensations, ideas, and thoughts. It is thinking, one should say, like one says: It is raining ['es blitzt' in the German original]. To say cogito is already too much, as soon as one translates it into I think." 2 That is to say: Experiences take place, and that is allthere is not, over and above them, an "I" that has them.

Yet, on the other hand: Experiences do not just lie about like stones or chairs, equally accessible to everyone. In my experiencing them, my experiences are given to $m e$ in a totally different way than to anyone else, and are in this sense the experiences $I$ have or $I$ experience. "Experiences are not in a nowhere-land", as Husserl once said, ${ }^{3}$ but "in me". It may be that when I introspect I can find only ever-changing experiences and no "self", but it is $I$ who only finds these experiences-namely my experiences ${ }^{4}$ : They are experienced by me and not by you. It can hardly be denied that experiences are in each case someone's experiences. So again: What are these "someones"? What are these different "I"s "in which" experiences take place (if they do not take place in a "nowhere-land")? What peculiar kind of "place" is this?

So, although the observation that we can find no self might at first appear intriguing, it now seems that we have been searching in the wrong place: The "I" is

\footnotetext{
${ }^{2}$ Lichtenberg (1971, p. 412).

${ }^{3}$ Husserl (1956, p. 166).

${ }^{4}$ Cf. Chisholm (1979, pp. 39-41).
} 
not to be found as some observable object, but in the fact of the mineness of my experiences. ${ }^{5}$

Yet it could be objected that it is perhaps too rash to deduce from this "mineness" the existence of an "owner" that is distinct from the experiences it owns. Perhaps the mineness is simply the mode of existence of experiences and does not presuppose a subject, but rather constitutes it. In this sense, the phenomenologist Dan Zahavi writes: "The subject or self referred to in self-awareness is not something apart from or beyond the experience [...] but simply a feature or function of its givenness." 6 "It is the very first-personal mode of presentation of the experience [...] which constitutes the self in its most basic form." ${ }^{\prime}$-So in this view the "mineness" of experience does not refer to its being-owned by an ego but simply to its original mode of manifestation. Experiences are not mine because some experience-transcendent "I" has them. Rather, this mineness (on the basis of which I say that "I" have an experience) is an intrinsic feature of the experience itself, so that it would be more appropriate-as Zahavi suggests-to speak of the "subjectivity of experience" rather than of a "subject of experience". 8

From this perspective, one could say that experiences take place in being firstpersonally given without thereby presupposing a "first person", since this very givenness-event itself constitutes the "dative" of givenness. In other words: The subject of consciousness is simply consciousness itself. Consciousness of something is consciousness of this something by virtue of being - to use Sartre's nomenclature- "conscious (of) itself", i.e. on the basis of its primordial self-manifestation. Therefore "I" am primarily not something that has consciousness but simply consciousness itself-in its essential self-intimating givenness-in-mineness.

So, in this view, in a certain sense it seems to be true that experiences basically just take place, without an owner-it is just that "to take place" means "to be consciously experienced" in the case of experiences, but this being-conscious of experience does not presuppose a subject of consciousness beyond the experience itself. Experiences are their own "stage" of appearance."

\section{Transtemporal identity and Parfitian reductionism}

Yet of course when I say "I" I do not just mean this present experience. With "I" I mean something that can have experiences other than just the presently experienced one and which actually has different experiences from moment to

\footnotetext{
5 Cf. Zahavi (2000, pp. 59-64).

6 Zahavi (1999, p. 12; cf. 2000, p. 62).

7 Zahavi (1999, p. 144).

8 Zahavi (2000, p. 61; 2005, p. 126). Quite in a similar vein, Galen Strawson suggests in Strawson (2003) — where he claims the identity of experience, content of experience, and subject of experiencethat it might be elucidating to conceive of the subject of experience as "an event or episode of subjectivity" (p. 304), which is nothing but the experience itself (cf. also Strawson 1999, p. 118).

9 As will later become obvious, I do have some sympathy for the view that the self is nothing but consciousness itself, but in a sense that requires further clarification of the relation between consciousness and content of consciousness (comparable to the views of Deikman 1999 and Shear 1999).
} 
moment. Hence, there is obviously a certain transcendence of the "I" with regard to individual experiences. There are not simply successive experiences, each with its own "mineness" (first-personal givenness), but rather it is $I$ who has this experience now and that experience then. And based on this, I have a clear intuition of what it means for some future or past experience to be experienced by me.-Yet, what does it mean? What is it that remains the same throughout all the changing experiences? A state of consciousness now and a state of consciousness in some more or less distant future are evidently different states of consciousness. What makes them states of the "same" consciousness, and what is the nature of this "sameness" (i.e. the nature of the transtemporal identity of the experiencing "I")?

A denier of a distinct "ego" or "self" does not have to claim that the different experiences have nothing at all to do with each other. She can of course acknowledge that the experiences of one stream of consciousness are strongly connected to one another in a way that they are never connected to experiences of other streams. She only has to reject the assumption that they are connected through being experienced by one and the same subject and instead claim that the oneness of "one subjectivity" consists in the connectedness of the experiences. ${ }^{10}$ There is no denying that in their streaming, experiences integrate themselves into one stream of consciousness. But that is about it. The transtemporal unity of consciousness is a result of a self-unification of experiences and not due to an enduring "I". So, in this view, what we call the "identity" of our self consists in certain relations between "our" experiences that bind them together (relations of memory, continuing intentions and character traits, etc.). "My" experiences are not united by having a common relationship to the same "I" (me), but simply by certain relations that hold between them. Hence, there is something like "one subjectivity" to which the single experiences belong, but this is no "owner" of its experiences but rather (in one way or another) constituted by the experiences and their interrelations. This amounts to what Derek Parfit calls (and espouses as) the "reductionist" view of personal identity. "Reductionism" here refers to the thesis that the subject's identity consists in something else (something more fundamental)-namely certain interexperiential relations (or also relations of experiences to one and the same body) to which it is therefore reducible. It stands opposed to substantialist (Cartesian) views that hold that the identity of the self does not consist in anything else, but literally means the remaining-the-same of the ego who has the experiences.Today, this latter position is clearly in the minority, ${ }^{12}$ while the debate about "personal identity" is mainly concerned with the question of which particular relations personal identity consists in, thereby presupposing the validity of the basic reductionist claim.

Returning now to the phenomenological account that sees the origin of the mineness of experience in its first-personal mode of givenness, where is it to be positioned within this opposition of relationism/reductionism and substantialism/ non-reductionism?-This account holds that the origin of what is meant by

\footnotetext{
10 Cf., e.g., Strawson (1999, p. 119).

11 Parfit (1987, pp. 210-211).

12 Examples are Chisholm (1979), Swinburne (1984), Foster (1991), Lund (2005).
} 
experiences being mine does not lie in their belonging to an "I" that would be in some way distinct from the experiences, but in their givenness in a first-personal way, "as mine". When experiences elapse into the past, in no way do they simply vanish into phenomenal nothingness; and this elapsing also does not mean a total estrangement: They continue to be accessible "as mine", "from the inside", as it were. A past experience can be first-personally given no less than a current experience, and there is no further act of identification involved, any more than there is with a current experience (I would never ask "I remember a past experience, but whose was it?"- no "error of misidentification" is possible here ${ }^{13}$ ). So the mode of givenness of my experiences is clearly distinct from that of the experiences of others, temporal distance notwithstanding.

But the crucial question is: Are my experiences given in a different way than others' because they are mine, or are they mine only insofar as and because they are given that way? That is to say: Are past experiences only mine by virtue of being given in my present experience "as mine" (first-personally)? After all, a past experience is given first-personally not only to my present experience, but was also, and primarily, thus given to itself when it was present-what is the relation of these "minenesses"? Is the "sameness" of mineness constituted by retaining the past mineness in my present mineness? Is the past experience, in its present givenness as mine, revealed as having been mine, or does its mineness mean nothing other than that it is now given that way? The latter view again amounts to a reductionist account of the identity of the self, since then this identity is constituted by a certain relatedness of experiences. ${ }^{14}$

The view that the oneness of "one mind" means that various experiences are unified, and that this unification is due to some inter-experiential relations is certainly not utterly implausible. On the contrary, as a matter of fact, prima facie, it seems to be nearly self-evident-how could it be otherwise? Yet on closer inspection, as the debate about personal identity brought to light, it turns out to have highly counter-intuitive implications.

These implications are due to the fact that concepts like "connectedness" or "continuity" allow for degrees and also, at least in principle, for splitting and merging - conceptual possibilities that are quite incompatible with our intuition of what it means for a future or past experience to be mine. ${ }^{15}$ Experiences can be more or less unified, borderline cases are possible where only an arbitrary decision can determine whether something should or should not count as belonging to a unit of bound-together items. But can experiences be more or less mine? Can there be borderline cases of mineness? Is it not necessarily the case that each experience is either experienced by me or not, without any in-between? And is not the question of whether it is the one or the other a real difference and not just a question of referring to the same matter of fact in different ways?

\footnotetext{
${ }^{13}$ Shoemaker (1975); cf. Zahavi (1999, p. 145).

${ }^{14}$ A "non-egological" view of subjectivity along such lines was espoused by many phenomenologists: Cf. for example Sartre (1957), Gurwitsch (1941), but also Husserl in his early years (e.g. Husserl 1984, pp. 363-364).

${ }^{15}$ Cf., e.g., Swinburne (1973/1974, 1984).
} 
In my view, one of Parfit's strengths is the clarity with which he works out the counter-intuitive consequences of his reductionist view and embraces them, dismissing our everyday intuitions as erroneous. This is the way he employs, for example, his notorious "teletransportation" thought-experiments ${ }^{16}$ : Teletransportation means a fictitious future way of travelling by dissolving my body here (say, on Earth) and instantly replicating it-including every detail of my brain structure and thereby, assumedly, all of my psychological traits and memories-somewhere else (e.g. on Mars). My replica is clearly aware of having been on Earth a moment ago and has all the character traits, plans etc. I had: According to any psychological criterion of personal identity he $i s$ me. Now Parfit tells a story of a victim of device malfunction: He gets replicated on Mars, but still remains undissolved on Earth. He is deeply shocked: the person on Mars is not him; he is just someone like him who believes himself to be him. But he is the person here on Earth. So it seems that even if the teletransportation device had functioned in the usual way, this replica would not have been him either. And he would have been killed.

However, Parfit insists that this shock would be irrational: For, if there is not something like a spiritual "ego"-entity (which we simply have no reason to believe in), what we fear might not happen in teletransportation-namely the transportation of my "I"-never happens at all. ${ }^{17}$ My survival from moment to moment never involved more than the future existence of experiences which stand in the right relation to former experiences. There has never been anything like a surviving "I" (or, if you will, the survival of my "I" (of me) consists in these relations).

So "what matters" with regard to my survival, according to Parfit, is the future existence of experiences that stand in the right relation to my present ones. If there would be-e.g. in the imagined duplication case-several persons whose experiences meet this condition: so much the better. Double survival cannot be equated with death. If one of the two persons would lead a happy and fulfilled life and the other would suffer miserably, there would be no point in hoping to be the one and not the other: The question "Who of these persons will be me?" is simply meaningless-for there is no "I" that could be either of them. ${ }^{18}$

Yet this is quite hard to accommodate with our intuition of what it means for an experience to be mine. The logical possibility of duplication forces upon us the intuition that there must be more to being me than merely some continuity-relations between experiences - there must be some "extra-ingredient" that makes experiences mine. "From the point of view of the person himself", as Thomas Nagel observes, "the question of his identity or nonidentity with someone undergoing some experience in the future appears to have a content that cannot be exhausted by any account of memory, similarity of character, or physical continuity." 19

\footnotetext{
${ }^{16}$ Parfit (1987, pp. 199-201).

${ }^{17}$ Parfit (1987, pp. 279-280).

${ }^{18}$ Parfit admits that we would not speak of identity in this case-but not because there would be less survival but because there would be double survival, which — since identity is a one-one relation-forbids us to speak of identity here. But this is just a question of words. There is nothing this double survival lacks in comparison to normal survival (survival with identity), quite on the contrary (Parfit 1975, 1987, pp. 261-262).
}

19 Nagel (1979, p. 200). 
Not only does it seem thinkable that experiences that are sufficiently continuous with my present ones are nonetheless not mine, but also that future experiences which are not thus related to my present experiencing are nevertheless mine. This becomes evident when one considers-along the lines of a famous thoughtexperiment by Bernard Williams ${ }^{20}$ - that the prospect of being tortured would lose nothing of its horror if the prospect of suffering complete amnesia and a profound change of character beforehand would be added: this would not convince me that I have no reason to fear the torture (i.e., it would be of little comfort if a reductionist assured me that, per definition, the person in pain will not be me), rather, I would be even more dismayed, because not only would torture await me, but also total mental derangement. This does not really make the prospect more pleasant. As Geoffrey Madell rightly observed, what I am afraid of is not that there will be pain accompanied by memories of my present experiences, but simply that it will be me who will be in pain - and it does not seem that both mean the same thing. ${ }^{21}$ So obviously, with the "mineness" of future or past experiences we mean something that is irreducible to any connectednesses between experiences. It appears that no rupture in the stream of consciousness could rule out a priori some future experience being mine.-But if it is conceivable that I might have experiences that are completely divorced from my present ones-what is it then that makes them mine? If there is a clear difference between a future person no longer being me and his being me but profoundly changed (to whatever extent) — in what does this difference consist?

While one could be tempted to dismiss the duplication scenario as being totally fictitious (although split-brain cases might suggest otherwise), the amnesia case is not that far-fetched. One can, for example, imagine suffering from Alzheimer's disease and anxiously wonder what it will be like in its final, highly dissociated stages - and whether the sufferer will really still be oneself. For Parfit, this would be what he calls an "empty question", ${ }^{22}$ and he would reply that you could call it this or that, but that this does not designate any real difference. Yet of course such an answer would be highly unsatisfactory: One can hardly avoid being convinced that any future experience is either mine or not mine, and that this is not a question of arbitrary definition or convention-and that it makes even less sense to say that it is partly mine, partly someone else's. ${ }^{23}$

\footnotetext{
${ }^{20}$ Williams (1973, pp. 51-52).

${ }^{21}$ Cf. Madell (1981, pp. 15, 110). Cf. also Chisholm (1979, p. 111).

${ }^{22}$ Parfit (1987, pp. 213-214).

${ }^{23}$ Cf. Williams (1973, pp. 58-61).-Of course both scenarios seem to suggest sticking to the bodily criterion (which is precisely Williams' point). Yet, though it might of course well be that all experiences that are mine are associated with this particular physical body (or at least the brain), this is at any rate no analytical truth (e.g., there is no logical contradiction in the idea that my brain gives rise to two streams of consciousness, i.e. also to experiences which are not mine). And since "I" is a rigid designator whose reference is furthermore determined by an essential property (namely being me), the logical possibility of this particular body "having" experiences which are not mine means that the relation between this body and me cannot possibly be identity (cf. Kripke 1980). So this body and its transtemporal identity is not what my being me consists in-my experiences are not mine by virtue of belonging to my body, rather this body is $m y$ body by virtue of being linked in a special way to my experiences, i.e. by being the body through which $I$ experience the world.
} 


\section{3 "This" and "I"}

So our intuitions strongly suggest that whatever relations between experiences we choose to define the transtemporal "identity" of a mind, they can serve neither (as the duplication scenario shows) as a sufficient, nor (as the amnesia case shows) as a necessary condition for an experience to be mine.-But perhaps these intuitions are simply wrong. Perhaps there is really no more to the "mineness" of experiences than that, for each experience, this experience itself and certain previous experiences are given "first-personally", and that this permanently transpiring self-integration of the stream of consciousness constitutes the unity of "one mind"-and that the idea that there might be a mineness of experiences beyond and independently of this, a mineness derived from the sameness of the "I" that has them (a sameness that is consequently not constituted by the self-integration of the stream of consciousness) is simply an illusion.

But even if we should grant this, the enigma of what the mineness of experience means-what it means that it is me who has my experiences-remains, as far as I see, unresolved. The enigma of mineness does not just concern the question of what makes some future or past experience mine, it already concerns this very present experience, taken by itself: What makes it mine?-We have to ask what it means to be me before we can tackle the question of what it might mean to remain me. (And whatever it is that makes my present experience mine: this and nothing else is probably what makes any past and future experience mine.)

We considered the view that the mineness of experience does not mean that some ego-entity has it, but that it is rather a feature of its original givenness: An experience exists by virtue of manifesting itself in a first-personal way, and the "first person", the experiential "I", is nothing but a function of this mode of givenness, and not an owner that would exist in addition to this experience. In a way this sounds perfectly convincing. But nonetheless it does not seem to be sufficient to ease the sense of puzzlement we feel when we begin to think about who it is who experiences the experiences. The question of what it means to say that it is me who has this present experience cannot be answered by referring to its property of "mineness" (i.e. first-personal givenness), for every experience that ever has been experienced possesses this feature. ${ }^{24}$ But only those experiences that are firstpersonally experienced by me are mine. The mineness of my experience is not some mineness but my mineness. What is this mineness of mineness?

This seems to be a rather bizarre question. In the Parfitian view there is actually no question about this. "My experience" means nothing more than "this experience, occurring in this particular mental life" ${ }^{25}$ : It is simply an indexical mode of reference. Of course all experiences can be "this" with regard to themselves respectively, but only one experience (and one stream of consciousness) is "this" with regard to this experience itself. There is nothing enigmatic about that.

Geoffrey Madell and others have replied that one cannot explain away the peculiarity of the first-person pronoun as being merely a case of indexical reference,

\footnotetext{
${ }^{24}$ Cf. Lund (2005, p. 118)

${ }^{25}$ Parfit (1987, p. 517).
} 
because, on the contrary, all indexical expressions are in their reference parasitic on "I"26. "Here" is where $I$ am, "this" is what $I$ am pointing at, etc. And "this" experience is "this" with regard to me: the one $I$ experience. If all indexical reference presupposes the first person there seems to be no point in trying to eliminate "I" through "this".-But Parfit denies this dependency of "this" on "I", rather, he claims, the meaning of all indexical expressions, including "I", can be explained through the meaning of "this", namely in its "self-referring use". Just as "this" in this very sentence simply refers to the sentence of which it is part (instead of something $I$ am pointing at), a thought can refer to itself and to the "mental life" whose part it is. ${ }^{27}$ There is no "I" that "has" its stream of consciousness- "I" is just an indexical way of designation with which a thought refers to the stream of consciousness (or the "person" that is constituted by this stream) to which it belongs.

Of course this presupposes the thought's ability to refer to itself (as itself). But this can be seen as founded in the primal self-givenness of experience, which is simply its genuine mode of being and does not require some "I" that has it.

But does "I" really mean "this unified stream of consciousness"? ${ }^{28}$ - Sometimes I might wish to be someone else (i.e. another person, with totally different experiences and even different character traits). This wish may be quite hard to satisfy, but it seems to have a clearly conceivable meaning: It is not the wish for something contradictory; it is just de facto not the case. But how is this possible? If "I" were to refer indexically to the stream of consciousness the present (in this case the wishing) experience belongs to, this would obviously have no meaning at all. How could this stream of consciousness be another stream of consciousness? It simply would not be this stream of consciousness then. Who or what shouldaccording to my wish-be another person and have completely different experiences? I do not wish that I would not exist and instead of me someone else, someone happier-I would not give a dime for that. I wish $I$ were this other person and would go through different experiences.

That I can imagine being someone else seems to be incompatible with the logic of "this". I cannot sensibly say: "This desk could as well have been another desk." Of course another desk could be standing in front of me, and probably I would refer to it with "this desk" - but nonetheless it would not be this desk, it would be another desk (another desk I would then call "this desk"). "This" is- to use Saul Kripke's terminology — a rigid designator ${ }^{29}$ : Although referring via a contingent property (namely "standing in front of me"), it refers rigidly: For example I can sensibly say "This desk could as well not be standing here"-in this counterfactual case I would not call it "this desk", but it would nonetheless be this desk (i.e. the

\footnotetext{
26 Madell (1981, pp. 39-40), Klawonn (1990, p. 45).

27 Parfit (1987, p. 252).

28 For brevity's sake I use the phrase "this stream of consciousness" instead of the probably more adequate "this 'person' that is constituted by this stream of consciousness (scil. the stream of consciousness of which this very ' $\mathrm{I}$ '-thought is a part) and a certain body this stream is associated with", or the like; for our purposes it makes no difference whether the subject is taken to be identical or reducible to the stream of consciousness.

29 Kripke (1980, p. 10).
} 
desk I refer to with "this desk" in the actual situation, in which I am, after all, speaking about the counterfactual one). So this very desk could impossibly be this desk while being another desk; I cannot even meaningfully wish for this. But I can wish to be someone else and to have completely different experiences. So obviously "I" cannot mean "this stream of consciousness".

This is even more obvious when it comes to the opposite case: when I wish (or imagine) that the very person I am (with all his physical and mental properties) would not be me. Again there is no analogy in the case of "this": It makes no sense at all to say: "I wish this desk, with all its properties, its history and location, would not be this of all things." It is totally incomprehensible what this should mean: How could it be another desk if all its objective properties were just the same? There is simply no logical room for a further difference. Only the subjectivity of experience involves a further dimension that allows for a difference over and above all objective facts, namely the subject itself.

With regard to this disanalogy between "this" and "I", Parfit's "self-referring use" of "this" is of no help. A sentence like "This sentence could exist with all its properties except that it would not be this sentence" is pure nonsense. Nor can I sensibly say: "This sentence could as well have been another sentence": it would simply not be this sentence then; it would be another sentence that, perhaps, would also refer to itself with "this"-just as there are other persons who refer to themselves with "I", which does not make them be me. In the case of "I" there is a clear difference between I being another person and another person being "an I" (i.e. herself) — and it is precisely this difference that has no analogy in the case of "this".

The basis of the difference between "this" and "I" is the intuition that there exists a logical contingency in the fact that I experience the experiences I actually do, i.e. in the fact that "this stream of consciousness" is " $m y$ stream of consciousness" - a contingency that is hard to explain if the latter were to mean nothing more than the former. This stream of consciousness cannot be contingently this stream.

It is precisely this contingency-intuition that occasionally gives rise to a rather strange experience of perplexity. Perhaps everyone, at least once in one's lifetime (probably sometime in childhood), is struck with an unsettling puzzlement about one's own being oneself, i.e. about the fact that it is oneself who is who one is ${ }^{30}$-a puzzlement that is quite hard to put into words (and the child will probably either not even try to communicate it or quickly give it up).

For example, a child might ask, after having learned about the biological origins of individual life: What if, when I was conceived, a different sperm would have won the race and fertilized the ovum-what would I be like then? Would I be very different? Or would I not be at all ${ }^{31}$ The answer seems to be quite clear: In such a case this child would simply not have existed at all. But the seeming obviousness of this answer will not change anything in the bafflement that has arisen in the child about the elusive difference between being different and not being at all. And she

\footnotetext{
${ }^{30}$ Cf. Spiegelberg (1961).

31 Cf. Nida-Rümelin (2006, pp. 13-14) for an auto-report about a similar childhood conversation.
} 
might continue asking: What if this particular sperm that actually won the race would indeed have won it, but for some reason the result of the fusion would have been genetically slightly different than it actually was: Would I then have been different, or not at all? What amount of difference, or what particular difference, would have the consequence that I would not have existed and instead of me someone else? What kind (and this is the central puzzle in all this) of difference is this, after all-what does it mean that $I$ am who I am?-And: could not everything have been exactly the same, except that the resulting person would not have been me? What is this being-me?

These are nothing but "empty questions" in a Parfitian view. But I believe they are meaningful ones (one cannot help but find that, from the subjective perspective, the difference between one's own existence and non-existence seems to be very real), and the moment they emerge they give rise to a profound feeling of puzzlement: a puzzlement about the seemingly trivial fact that the person one is exists as oneself, and about what it means to be oneself at all. Strangely, it appears to be a contingent fact that one is the person one is. ${ }^{32}$ No third-personally formulated feature of the person I am (be it his body, personality, or experiences) seems to logically imply that this person is not just "an I", but me-no more than any feature would make it logically impossible that the person in question is me. ${ }^{33}$ So the person I am with all his experiences could have existed, doing what I do, experience what I experience, with the only difference being that he would not be me. Nothing would have been different for anyone, except for me: I would not have existed. A strange difference, indeed-as Erich Klawonn puts it: "a paradoxical difference, which makes no difference". ${ }^{34}$ What makes the difference here (i.e. me) is in no way objectively characterizable. And this means: That I am me (the person I am) is a "further truth" over and above all objective truths (be they physical or mental). ${ }^{35}$ This is quite astonishing. ${ }^{36}$

\footnotetext{
32 And consequently, "I am this particular person" cannot be an identity statement then, but rather appears to be something like a subject-predicate proposition (Nagel 1986, pp. 55, 60).

33 Madell discusses and vindicates these logical possibilities in length in his Identity of the Self under the labels "distinct" and "alternative biographies" (cf. Madell 1981, Chap. 4).

34 Klawonn (1987, p. 52).

35 Nagel (1986, pp. 55-56).

${ }^{36}$ It has been argued that the (purportedly erroneous) intuition that I could be someone else derives from the nature of indexical reference, namely to refer without ascribing any properties to the referent (e.g. Coval 1966, pp. 37-38). The term "I" is conceptually compatible with any set of properties (so that I can refer to myself without knowing any objective facts about me, which produces the illusion that my self is something over and above all these objective facts); yet, in fact, this in no way implies that the object it refers to had the properties it has only contingently. What is an epistemic possibility may not be a metaphysical one.-This line of argument, however, lacks plausibility. It is true that when I say "here" this might be anywhere, without the place it refers to not being essentially where it is. But as soon as I know where "here" is, I cannot imagine this very place being somewhere else. Yet even when we know who we are and of course are aware of the experiences we are presently having, we can clearly imagine being someone else and having different experiences.
} 


\section{4 "I" as dimension: experiences and their presence}

The puzzlements about my identity over time as well as about what makes the present experience mine are fuelled by the intuition that being mine is an additional feature of an experience over and above all its other properties, its relations and its being-given-to-itself. What legitimizes this intuition? The sceptic will not be convinced by the alleged logical possibilities described above. If she considers the intuition that I could have past or future experiences that are completely divorced from my present ones to be erroneous, she will a fortiori dismiss the counterfactual speculations that I could as well have been another person as being utter nonsense. ${ }^{37}$ So again, whence does the intuition of the non-constituted transcendence of the "I" with regard to its experiences, and thereby of the contingency of my having the experiences I have, derive its legitimacy?

The reductionist view holds that the identity of the experiencer throughout her experiences consists in (=is reducible to) certain relations between the experiences, and that means it is constituted by a synthesis of the experiences which unifies them. So the transcendence of the presently experienced mineness of my current experience with regard to this very experience just means that there are other, past and future, experiences that stand in the right, unifying relation to it. Is this synthesis of experience really the ultimate source of the subject's transcendence with regard to the individual experiences (and in consequence of its ability to-then erroneously-imagine having completely different experiences)? It might be expedient here to have a closer look at the nature of the individual experiences themselves whose synthesis is supposed to yield this trans-experiential identity of the subject. To put it differently: If the transtemporal identity of the subject consists in some "unity relation" between "subject-stages" 38 - then what is such a "subjectstage"?

My present experience is undoubtedly mine-there is no need for an identificatory attribution of this experience to my "ego". Rather, the original givenness of the present experience in its being-experienced is the very origin of the meaning of "my" (i.e., it is not thus given and then attributed to myself). Other experiences are supposed to be mine by virtue of some relation in which they stand to this present one. But what is the "present experience"? In a certain sense there is not only one present experience. Rather, I am momentarily undergoing manifold experiences: I see my notebook in front of me, I hear the traffic from the street, I feel the keyboard beneath my fingers, I think about how to formulate the next sentence, and so on. What makes it so that all these experiences are unified in one experiential presence (i.e., what accounts for the "synchronic unity" of consciousness)? ${ }^{39}$ Parfit sees no problem here: Manifold experiential contents are synchronically unified

\footnotetext{
37 Cf., e.g., Williams (1973, pp. 42-45).

38 Cf. Perry (1975).

39 One could object that these are not really several experiences but only one total experience of a complex content. This is perfectly fine with me-but the question is precisely what makes it one experience. Obviously nothing on the content-side can do this job.
} 
simply by being present in "a single state of awareness". ${ }^{40}$ This seems perfectly sound. Yet what is this "single state of awareness"?

Can we conceive of this synchronic togetherness of experiential contents as a synthesis of these contents that somehow binds them together? The problem is that "state of awareness" designates nothing other than the experiences' being conscious-and for an experience to be means to be thus consciously experienced (to manifest itself first-personally). No binding-together of per se unconscious data could ever yield their being-conscious. ${ }^{41}$ So if the oneness of the "single state of awareness" is to be the result of a synthesis of experiences, each experience already has to be conscious in its own right, independently of this synthesis. But if each experience has its "own" consciousness, it is quite unclear how these "consciousnesses" should fuse into one consciousness in which all these experiences are simultaneously present. How should we conceive of this? Is each experience co-conscious of its "neighbouring" experiences? If that were true then "I" would obviously have to be one of those experiences (which one?), an experience that is co-aware of the other experiences, which are nonetheless already conscious in themselves - a more than implausible view.

No, rather the single state of awareness is the one experiencing, in which the manifold simultaneously co-conscious experiences have their original and only being-experienced (their "primary presence" ${ }^{42}$ ). Here it becomes obvious that it necessary to distinguish between two meanings of the term "experience" that we have so far not discriminated: There is a tendency to equate "experience" with the experienced, i.e. the experiential content (e.g. to call visual data "experiences"); but it can as well mean the experiencing itself in which the experienced is experienced (i.e. has its experiential presence). ${ }^{43}$ In a way, it indeed seems to be correct to say that the "I" is nothing that transcends the experience as something that "has" it, but then "experience" has to be understood in the latter sense, as the act of experiencing, and as this I am neither one of the experiential contents, nor their sum, nor constituted by relations between them, but the event of their being-present, their medium of manifestation. Presence does not consist of the present contents but is what makes them present. ${ }^{44}$

Hence, the "one awareness" (the togetherness of the manifold synchronically co-conscious experiential contents) is not a result of any relations between the experiential contents, of some synthesis of them, ${ }^{45}$ but rather has-as Dieter

\footnotetext{
40 Parfit (1987, p. 250).

41 Cf. Henrich (1970, pp. 262-263).

42 Klawonn (1987, p. 64).

43 Cf. Zahavi (1999, p. 80).

44 So Hume is right when he says that I never introspectively find some special experiential content that could be my "self". "I" am rather the presence of the very contents I find. I am the "where" of finding (respectively, in a way, the finding itself).

45 Cf. Barry Dainton's discussion of Christopher Hill's rejection of a "ghostly form of co-consciousness" that does not consist in any other relations in Dainton (2006, pp. 240-244, esp. 243): "Synchronic phenomenal unity comes in different modes, but these modes all involve experienced togetherness. Being related by co-consciousness is thus a precondition for being related by any other mode of phenomenal unity [...]." Cf. also Dainton and Bayne (2005).
} 
Henrich suggests - the character of a dimension in which the contents, with all their relations, have their presence in the first place. ${ }^{46} \mathrm{~A}$ dimension, though perhaps never being without manifold related elements, is not the result of these relations, but is what makes them possible.-Therefore I would agree with the view that I am my consciousness, and not some entity that has or owns it, but this consciousness is the one experiencing, the one presence as the realm of existence of the many experiential contents (and consequently "transcendent" with regard to them, whilst not being a result of a synthesis between them). ${ }^{47}$

Now the question is: What is the nature of the temporal abiding of experiential presence as the dimension of first-personal presentation through the permanent succession of experiential contents? Can it come about by relations between the contents? Is there a succession of presences together with the succession of contents? Yet if, as we have seen, it is not the case that each content has its "own" presence, is it then plausible that the presence (the awareness) comes and goes with the content, somehow unified into "one awareness"? If the oneness of awareness is not constituted by inter-experiential relations on the synchronic level, is this then diachronically possible?

Let us again have a look at the nature of the "present experience" whose relations to other experiences should constitute the "permanence" of presence. Actually, experiences are exclusively present as streaming: Experiential presence is always and only the presence of streaming experiences as streaming. I permanently experience the passing of experience that transpires in each present (and therefore my present living through these ever-streaming experiences). So the present presence is the presence of the present taking place of the streaming of experienceand that means: Presence is irreducibly presence of temporal transition. Presence of transition does not just mean that in each moment there is consciousness of a now together with a consciousness of a no-longer-now, as having just elapsed; it means, rather, the experiencing of the present taking place of transition itself, ${ }^{48}$ which

\footnotetext{
46 Henrich (1970, p. 277); cf. also Klawonn (1987, p. 62).

47 Cf. Deikman (1999). Dainton argues against Deikman's claim that the "awareness" in which the contents have their presence can be distinguished from these contents as being misled by a perceptionmodel of consciousness (Dainton 2006, pp. 44-46): It misinterprets a phrase like "I feel pain" as if pain were an object I observe-but actually in being aware of our experiences we do not direct our "gaze" at them, for any experience only exists in being experienced; there is no distance between our experiences and our "looking" at them.-However, I think Dainton crudely misrepresents the meaning of Deikman's view in his critique. He takes it to claim that consciousness is "inherently bi-polar" (ibid., p. 41)—but (although this might be suggested by some of Deikman's formulations) "awareness" is no pole, it is not a "something" that would be opposed to the content (the "object-pole"). Rather, it designates nothing more than the presence of the content. Awareness and content are not "distinct ingredients" (ibid., p. 57) that were somehow "combined" (ibid., p. 51), thereby constituting experience, but the medium of existence of experience. There is no bi-polarity involved here, no more than space would be a pole opposed to spatial objects-yet still, both are not the same.-From this perspective Dainton's reasoning seems quite unsound when he says that it is totally unclear what ingredient awareness, being itself devoid of phenomenal features, should contribute to phenomenal experience so that it seemed that awareness is simply superfluous (ibid., pp. 49-50; cf. also Dainton 2005, p. 6). This is a quite unconvincing argument: One could equally ask what ingredient extension brings to colour and conclude from the fact that it does not contribute any colour-shading to it that colour can do just as well without extension.
}

48 Cf. Dainton (2005, p. 13). 
transpires in the very now. Each "now" I am aware of is only there for me as passing by, in its transition to the "no-longer-now" (for a moment is not now present and then elapses later on; rather, the very essence of the present is temporal transition, and it is precisely as such that it is present to us). And transition as such transcends the sheer now, but not as a synthesis between nows: For there simply is no now that could be synthesized with another now which would not already be in itself the momentary taking place of temporal transition-this is simply the essence of time. There is no givenness of a now except as passing - and that is: without the persistence of presence.

So experiential presence is "where" transition takes place (and in a way this very taking place itself) and it does consequently not itself elapse with what passes. There is no present experience that is not there as streaming, and that is as passing through the dimension of first-personal presence-which thereby abides as the "locus" of passage. The being-experienced of the streaming experiences as streaming implies the persistence of the presence-dimension, i.e. the abiding of the actuality of experiencing itself. There is no evidence of the present experience without the evidence of my abiding through the permanent streaming of the experiencebecause it is in this very abiding that the experiences have their evidence. ${ }^{49}$

Presence does not come and go with the streaming experiences; rather, it is the abiding of presence in which the permanent coming and going of the experiences consists. This abiding of presence cannot be thought as a case of the (constituted) persistence of an enduring object ${ }^{50}$ : An enduring object is there for me as enduring in my apprehension of streaming contents that pass by as temporal "stages" or "phases" of this object-the abiding presence, in contrast, can not be understood as an enduring, "inner-temporal" object in this sense, for its abidance is nothing other than the permanence of the taking place of temporal streaming itself (and of course the flow of time is not itself a temporal object); the persistence of presence therefore cannot be constituted by relations between passing contents that would be its "phases". It is not constituted by temporal phases, but is rather their generation. Therefore I, qua consciousness, am not the passing experiences, but rather the taking place of their passing, their manifestation as streaming in their passing, which does not pass with them: the abiding experiencing of the changing experiences. $^{51,52}$

\footnotetext{
49 This is what Husserl called the "living present", as the fundamental being of subjectivity, which he characterizes as "standing-streaming" (2006, pp. 145, 124, 185 et pass.): It is "streaming" insofar as it is the very taking place of the permanent streaming of experiencing itself, and it is "standing" precisely because of the permanence of this streaming (cf. Husserl 2002, p. 384).

${ }^{50}$ Cf. Husserl (2006, p. 202).

51 Cf. Zahavi (1999, pp. 80, 144).

52 Consequently, I agree with Dainton and Bayne in that all experiences of a single stream of phenomenally connected (co-conscious) experiences are co-personal (Dainton and Bayne 2005), but I would conceive of this as being only a sufficient condition, not a necessary one. Dainton and Bayne avoid the consequence of the impossibility of co-personality in cases of intermittent phases of unconsciousness, but they do so by introducing "experience producers" (e.g. brains) that should preserve personal identity through phases of unconsciousness by virtue of their continuous capacity of producing phenomenally connected experiences (cf. also Dainton 2005). Yet I fail to see any logical necessity of the persistence of an "experience producer" (in the causal sense) for there being future experiences that are mine.
} 


\section{Conclusion}

Our question was why we can hardly avoid the intuition that there is something about our being ourselves, respectively, that transcends every objective fact about our experiences and their relations, something that is not constituted by them but is in some sense their precondition; and whether this intuition can be shown to have any legitimacy. My suggestion now was that "the I" has to be conceived of as having the character of a dimension with regard to its experiences ${ }^{53}$ : It is neither the experiential contents nor is it constituted by relations between the contents, but it is the dimension of their presence in which the contents and all their possible relations have their primal manifestation (and thereby their existence). And it is the presence of contents in their streaming, the dimension of the permanent change of content, and as such does not itself change with the contents. ${ }^{54}$ - The idea that the "I" is more than just the present experience but something that can, as one and the same, have various experiences and could have other experiences, without this sameness being reducible to anything else (e.g. to any inter-experiential relations), has its root in the fact that every experience in its mere being-experienced essentially already implies a synchronic and diachronic transcendence of "me" qua consciousness with regard to this experience, a transcendence in which the being-experienced of the experience itself consists. It is not so much the transcendence of a "separately existing entity" (as Parfit thinks the necessary claim of the non-reductionist has to $\mathrm{be}^{55}$ ) but rather that of the dimension of first-personal manifestation of experience with regard to the experience. The fact that I, in this basic sense, am not constituted by the experiential contents and their relations is the origin and, as I believe, the source of legitimacy of the compelling intuition of the contingency of my having the experiences I have. No features of my experiences - no matter whether intrinsic or relational-can imply their being mine except their having their manifestation in this very dimension of first-personal presentation which has no other essential property than being me (what Smook 1988 calls "egoicity"): a dimension that is completely "subjective" (and in fact is nothing but subjectivity itself which constitutes the "subjective character" of conscious experience).

Acknowledgement This article was conceived and written in the framework of the Austrian Science Fund (FWF) research project "Consciousness without Content" (P18818-G15).

\footnotetext{
53 Instead of being to them "as the universe is to material things" (Gurwitsch 1941, p. 336). According to my view, it is rather like space than like the universe.

54 This corresponds, by the way, to the manner in which the self is conceived of in the Indian tradition of Advaita Vedanta: "I am Seeing, pure and by nature changeless" (Shankara 1992, I.10.2), "motionless like the sky" (ibid., I.10.9), "like space, [...] by nature not composite" (ibid., II.2.58). "It [atman = the self] is inwardly experienced as unbroken consciousness, the consciousness that I am I. It is the unchanging witness that experiences the ego, the intellect and the rest, with their various forms and changes" (Shankara 1978, p. 68).

55 Parfit (1987, p. 210).
} 


\section{References}

Chisholm, Roderick. 1979. Person and object: A metaphysical study. Chicago: Open Court.

Coval, Samuel. 1966. Scepticism and the first person. London: Methuen.

Dainton, Barry. 2005. The self and the phenomenal. In The self?, ed. Galen Strawson, 1-25. Malden: Blackwell.

Dainton, Barry. 2006. Stream of consciousness: Unity and continuity in conscious experience. London: Routledge.

Dainton, Barry, and Tim Bayne. 2005. Consciousness as a guide to personal persistence. The Australasian Journal of Philosophy 83 (4): 549-571.

Deikman, Arthur J. 1999. "I" = awareness. In Models of the self, ed. Shaun Gallagher and Jonathan Shear, 421-427. Thorverton: Imprint Academic.

Foster, John. 1991. The immaterial self: A defence of the Cartesian dualist conception of the mind. London: Routledge.

Gurwitsch, Aron. 1941. A non-egological conception of consciousness. Philosophy and Phenomenological Research 1: 325-338.

Henrich, Dieter. 1970. Selbstbewußtsein: Kritische Einleitung in eine Theorie. In Hermeneutik und Dialektik, vol. 1, ed. Rüdiger Bubner, Konrad Cramer, and Reiner Wiehl, 257-284. Tübingen: Mohr.

Husserl, Edmund. 1956. Erste Philosophie (1923/24). Erster Teil: Kritische Ideengeschichte, ed. Rudolf Boehm. Den Haag: Nijhoff (Husserliana VII).

Husserl, Edmund. 1984. Logische Untersuchungen. Zweiter Band, Erster Teil: Untersuchungen zur Phänomenologie und Theorie der Erkenntnis, ed. Ursula Panzer. Den Haag: Nijhoff (Husserliana $\mathrm{XIX} / 1)$.

Husserl, Edmund. 2002. Zur phänomenologischen Reduktion. Texte aus dem Nachlass (1926-1935), ed. Sebastian Luft. Dordrecht: Kluwer (Husserliana XXXIV).

Husserl, Edmund. 2006. Späte Texte über Zeitkonstitution (1929-1934). Die C-Manuskripte, ed. Dieter Lohmar. Dordrecht: Springer (Husserliana Materialien VIII).

Kapleau, Philip (ed.). 1980. The three pillars of Zen: Teaching, practice, and enlightenment. London: Rider.

Klawonn, Erich. 1987. The "I": On the ontology of first personal identity. Danish Yearbook of Philosophy 24: 43-75.

Klawonn, Erich. 1990. On personal identity: Defence of a form of non-reductionism. Danish Yearbook of Philosophy 25: 41-59.

Kripke, Saul A. 1980. Naming and necessity. Oxford: Basil Blackwell.

Lichtenberg, Georg C. 1971. Schriften und Briefe, vol. II: Sudelbücher II. München: Hanser.

Lund, David H. 2005. The conscious self: The immaterial center of subjective states. Amherst, NY: Humanity Books.

Madell, Geoffrey. 1981. The identity of the self. Edinburgh: Edinburgh University Press.

Nagel, Thomas. 1979. Mortal questions. Cambridge: Cambridge University Press.

Nagel, Thomas. 1986. The view from nowhere. New York: Oxford University Press.

Nida-Rümelin, Martine. 2006. Der Blick von innen: Zur transtemporalen Identität bewusstseinsfähiger Wesen. Frankfurt am Main: Suhrkamp.

Parfit, Derek. 1975. Personal identity. In Personal identity, ed. John Perry, 199-223. Berkeley: University of California Press.

Parfit, Derek. 1987. Reasons and persons. Oxford: Clarendon Press.

Perry, John. 1975. The problem of personal identity. In Personal identity, ed. John Perry, 3-30. Berkeley: University of California Press.

Sartre, Jean-Paul. 1957. The transcendence of the ego. New York: Noonday Press.

Shankara. 1978. Crest-jewel of discrimination (Viveka-Chudamani). Hollywood: Vedanta Press.

Shankara. 1992. A thousand teachings: The Upadesasahasri of Sankara (trans and ed.: Sengaku Mayeda). Albany: State University of New York Press.

Shear, Jonathan. 1999. Experiential clarification of the problem of self. In Models of the self, ed. Shaun Gallagher and Jonathan Shear, 407-420. Thorverton: Imprint Academic.

Shoemaker, Sydney. 1975. Personal identity and memory. In Personal identity, ed. John Perry, 119-134. Berkeley: University of California Press.

Smook, Roger. 1988. Egoicity and twins. Dialogue 27: 277-286. 
Spiegelberg, Herbert. 1961. On the "I-am-me" experience in childhood and adolescence. Psychologia 4: $135-146$.

Strawson, Galen. 1999. The self and the SESMET. Journal of Consciousness Studies 6 (4): 99-135.

Strawson, Galen. 2003. What is the relation between an experience, the subject of experience, and the content of experience? Philosophical Issues 13: 279-315.

Swinburne, Richard. 1973/1974. Personal identity. Proceedings of the Aristotelian Society 74: 231-248.

Swinburne, Richard. 1984. Personal identity: The dualist theory. In Personal identity, ed. Sydney Shoemaker and Richard Swinburne, 1-66. Oxford: Blackwell.

Williams, Bernard. 1973. Problems of the self: Philosophical papers 1956-1972. Cambridge: Cambridge University Press.

Zahavi, Dan. 1999. Self-awareness and alterity: A phenomenological investigation. Evanston: Northwestern University Press.

Zahavi, Dan. 2000. Self and consciousness. In Exploring the self. Philosophical and psychopathological perspectives on self-experience, ed. Dan Zahavi, 55-74. Amsterdam: John Benjamins.

Zahavi, Dan. 2005. Subjectivity and selfhood: Investigating the first-person perspective. Cambridge, MA, London: MIT Press. 